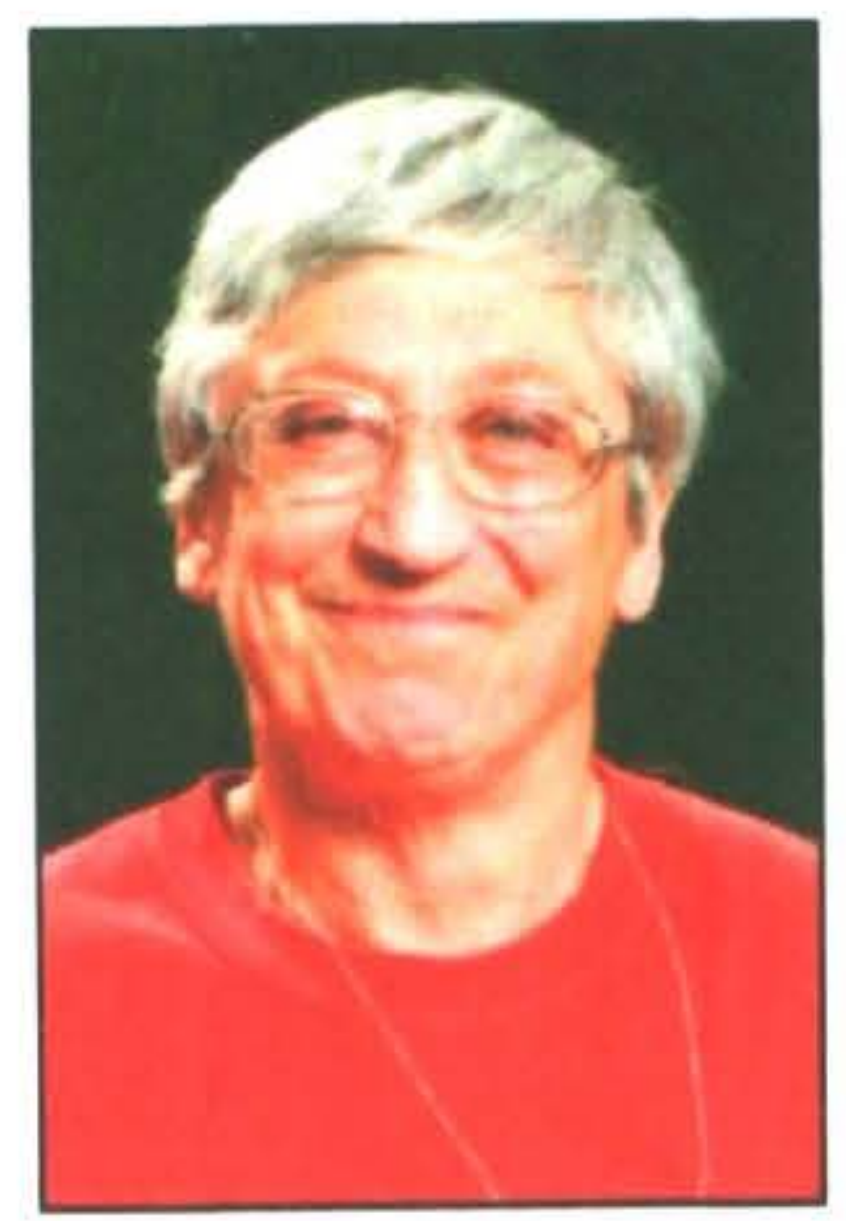

\title{
PAY EQUITY AND EQUAL EMPLOYMENT OPPORTUNITY IN \\ NEW ZEALAND: \\ DEVELOPMENTS 2006/2008 \\ AND EVALUATION
}

\author{
Prue Hyman
}

Adjunct Professor of Gender and Women's

Studies, Victoria University of Wellington

\begin{abstract}
This is the third in a series of LEW papers updating developments relating to pay equity and EEO and evaluating their impact. As with my previous papers, it focuses primarily on gender, but also discusses the overall situation and touches on issues related to ethnicity, age and disability. In the last two years the broad public sector, assisted by the Pay and Employment Equity Unit in the Department of Labour, has made significant progress in reporting on gender issues in most departments and in some parts of the public health and education sector, but practical action to reduce remaining gender pay gaps is a slow process. This paper will discuss these public sector processes and also the private sector situation in the context of a period where women have surpassed men in terms of education outcomes - and hence the need for vigilance around women's position in the labour market is increasingly questioned. With respect to ethnicity, despite non-discrimination legislation, there is substantial evidence of problems encountered by many immigrants entering the labour market. The paper will examine recent evidence on discrimination on the basis of ethnicity, age, and disability and reports/recommendations for its elimination.
\end{abstract}

\section{Introduction}

This is the third in a series of LEW papers updating developments relating to pay equity and EEO and evaluating their impact. My 2006 LEW paper concluded that reductions in gender and ethnic inequality in educational and other human capital acquisition have occurred partly from government action and partly in spite of it, and were likely to continue given social change, pressure from the groups previously denied equal access, and the economic imperatives to use all our labour resources fully. These factors were assessed to be of greater significance than legal requirements and policy initiatives towards employment equity (Hyman, 2008). These predictions were close to the mark, although the current world economic. financial, and credit turmoil makes ongoing progress more uncertain. This paper examines and evaluates developments in pay equity and equal employment opportunity in the last two years. It focuses mainly on gender issues but also touches on other dimensions of equal employment opportunity (EEO), including age, disability and ethnicity.

\section{Pay and employment equity in the broad public sector}

The establishment and early work of the Department of Labour's Pay and Employment Equity Unit, in accordance with recommendations from the 2004 Taskforce on Pay \& Employment Equity in the Public Service, Public Education and Public Health, was a major focus of my 2006 LEW paper. Since then, Phase One of the work has been almost completed, with 35 of the 39 core public service organisations having finished their reviews. In the public health sector, $5 \mathrm{DHBs}$ have completed reviews and others a validation process, leading to a Report and Response Plan which has gone to the Minister of Health. The public education sector is similarly placed with respect to schools and kindergartens. In Phase Two, local government has started its reviews, with Gisborne District and Waitakere City Councils the pioneers, together with three CRIs, while 14 polytechnics/institutes of technology and $\mathrm{Te}$ Wananga o Aotearoa are starting the tertiary education sector process and discussions are under way with universities. The Unit has provided tools and assistance to organisations undertaking reviews, with the processes streamlined and made more consistent, with a view to higher standards in later reviews. This was made possible through the development of the Pay and Employment Equity Analysis Tool (PEEAT), to help generate the relevant gender profiles from human resources data. The Unit's website, http://www.dol.govt.nz/services/PayAndEmploymentEqu ity/index.asp, is extremely informative, with case studies of reviews from a number of departments, detail of the tools used, and a regular newsletter.

The emerging themes from completed reviews are lower starting salaries for women, barriers to career development, lower performance pay, and pay gaps ranging from $3 \%$ to $25 \%$, varying by department and occupation. Women's incomes also tended to be lower in female dominated occupations. Some reviews found that 
such occupations received lower remuneration than male dominated occupations of similar job size - a major equal pay for work of equal value issue/pay equity. Several reports did not know if the job sizing had been done in a gender neutral manner, while others attributed the result to market factors, the issue which has long been the nub of the debate between equal value advocates and opponents. Comparisons are often made within roles, where the gaps are fairly small, though still important, bringing up EEO issues. However, it is the gaps between roles, raising equal value issues, where little is said other than to note that female median salaries are low in female dominated work.

A draft overview paper being prepared by the Pay and Employment Equity Unit includes material on pay and employment equity issues for several specific groups of employees. One such group is administrative/clerical support workers. "They have been recognised in many reviews as a group whose pay, opportunities and experiences of fairness and respect deserve attention. The DHBs response plan recommends investigating whether there is scope for a full pay investigation for clerical workers. In the majority of reviews administrative support staff have been found to be the lowest paid occupation, and in every case they are a femaledominated group. Administrative staff also typically have limited or no opportunities for career (and pay) progression. In some reviews they have been found to work overtime that is unpaid when other staff groups receive overtime pay. Some reviews have recommended a pay increase for these employees (and in some cases this has occurred already). A number of reviews have recommended that the pay of administrative staff be the subject of an in-house job evaluation. Some organisations have introduced limited career steps for clerical workers.

Ongoing monitoring is essential in this and many other areas, including starting salaries. One review saw this as simply a market issue, while others suggested educating managers and greater transparency about pay rates - the latter against many recent trends. The assumption that this would enable women to be able to bargain their starting rates more assertively, removing the gender disparity, is disputable. There is literature showing that gender related socialisation is an important factor on behaviour differences in this area. Consistency of offers based on standard criteria may be a better approach.

An informative forum was held in April 2008, organised by the Unit, in which its Director, Philippa Hall, outlined progress to date on these reviews, the tools, and the extension of the review process. One important upcoming development is a limited extension to the private sector, covering responsible contract policy for governmentfunded outsourced services in parts of the health sector. In November 2007, Cabinet agreed that pay and employment equity should extend to all DHB employees delivering services which a DHB has an operational obligation to ensure are provided, irrespective of whether they were employed directly by the DHB or by an organisation contracted to it. Another is a start on the first two pay investigations recommended by reviews, covering CYFS social workers and special education support workers. The latter work one to one with special needs children, and are a female dominated group, working part time and without security of tenure, earning from $\$ 13$ to $\$ 17.60$ per hour. The starting wage is now only just above the national minimum of $\$ 12$ per hour from April 1 2008. Gender neutral job evaluation (the EJE scheme) has been used to make comparisons of the value of the work against prison officers and hospital orderlies and the results will be available shortly.

Two other PEE sponsored projects under way are broader exercises to evaluate female dominated work in the services sector. The first is designed to identify and value hidden service sector skills common in female dominated jobs. In working with sick older people, the possible unnamed skills outlined included tact, taboos (managing to talk about areas normally too hard to raise - such as organ harvesting), tactility (subtle responsiveness to physical cues) and tacitness (fast responses to situations through unofficial knowledge). This approach has been used to generate a typology of three types of skill sets and levels in service work, awareness shaping, interaction/relationship shaping, and coordinating skills. The final product will include tools and guidelines for use in recruitment and performance management.

The second is the application of the Equitable Job Evaluation scheme, designed by PEE consultants, to community support workers for people with intellectual disabilities living in houses provided by the not for profit and private sectors. With very low wages determined primarily by public sector funding formulae, this female dominated job (top rate $\$ 16.20$ per hour: $76 \%$ female) makes emotional, sensory, and physical demands and carries responsibilities which could be missed in many job evaluation schemes. Employers, several of which were experiencing staff and skill shortages, supported the project, being powerless to raise wages unless the government is prepared to fund such increases. Comparators used were therapy assistants employed by DHBs, a fairly similar female underpaid group but higher paid than the support workers, and correction officers, a male dominated group with considerably higher pay than both. All were at ANZSCO skill level 4 and all were found to have similar total job point scores, albeit with different patterns on the various factors. Correction officers' pay increases with internal training to $\$ 51,257$, $\$ 17,551$ more than community social workers (DOL PEE Steering Group, 2008).

There is no policy or legislation enabling these results to yield pay increases, but they make a powerful union campaigning case, and one for employers to use in contact negotiations with government. All these detailed examples from the health and education sectors in caring. support and other services work, ultimately rely on increased government expenditure from taxation to fund adequate wages for undervalued female dominated work. Funder-provider splits, contracts for services and hands off industrial relations structures make it extremely hard to improve wages in these areas, particularly when government budgets are tight and economic crises loom. These issues will continue longterm, with improved 
medical knowledge and technology and greater longevity requiring ever more caring work, paid and unpaid. But with government expenditure under pressure, especially given the pre-election statements of the new National government, such funding is unlikely.

A case study of homecare by Janice Burns further reinforces the issues in female dominated caring work. Outlined on National Equal Opportunities Network (NEON), a partnership between the Human Rights Commission and the EEO Trust (website http://www.neon.org.nz/), this study outlined the triple bind faced by thousands of working women in New Zealand - poor pay, an under-valued female-dominated occupation and government-funded contracting arrangements for their industry. She concluded that solutions still appear elusive and constrained by an ideological straightjacket. She explained the way in which the contracting arrangements under the funder/provider split are highly non interventionist over staff conditions and stated that: "there appears to be no logical or empirical basis for the contract price currently offered to providers. Any institutional knowledge within the Ministry of Health on how the funding formula was established and how its currency is maintained seems to have long gone... At the moment the government funds at a level that does not support the pay and employment equity goals it supports for its own staff' (Burns, 2007).

\section{Burns recommended "four remedial steps:}

1. Undertake an assessment of the actual skills required for quality homecare work and the market rate for these skills

2. Assess the costs to the employer of building a quality and sustainable workforce

3. Develop a funding formula that fairly includes all the costs to provider businesses (including reasonable profit margins to assist business survival)

4. Develop government contracting minimum standards that requires evidence based on good labour practices of those receiving homecare provision contracts. This would include fair pay and employment conditions, meeting legal requirements around provisions such as sick leave and holiday pay, and covering all costs associated with the performance of the job" (ibid).

The National Advisory Council on the Employment of Women celebrated its $40^{\text {th }}$ anniversary in September 2007. Their review of the period and surveys of critical issues today are excellent resources (NACEW, 2007 and 2008). The latter includes arguments for the efficiency case, in addition to the equity case, for pay equity, or more particularly equal pay for work of equal value. "As well as considerations of fair pay, the lack of recognition of the full range of skills and responsibilities involved in many female dominated occupations is inefficient. Where occupations are undervalued, 'productive potential' tends to be constrained as a consequence of both inadequate recognition of qualifications, and limited access to training or career paths. The establishment of autonomy along with pay parity for midwives is an example of a productivity gain to society through the recognition that midwives had the skills to practice autonomously. NACEW supports the focus on achieving pay equity in the public sector being extended to the private sector in the near future" (NACEW 2008, p 15). NACEW's current work programme prioritises four areas: quality of work, Maori and Pacific Women's Employment, and caring and working.

Before turning to private sector issues and those covering all employees, it should be mentioned that the ongoing provisions of the State Sector Act, 1988, require Public Service CEOs to operate as 'good employers' which inter alia involve proactive Equal Employment Opportunities programme, covering at a minimum: Maori; women; ethnic minority groups; and persons with disabilities. Some monitoring of progress for each group ensures a degree of accountability and some progress has been made for all groups.

\section{Equal employment opportunity and the minimum code - gender and family issues}

In the private sector there are indicators showing that there is still a long way to go to achieve gender equality. These include the low representation of women in the modern apprenticeship scheme at one end of the employment spectrum and the miniscule improvement with respect to directorships of private sector companies at the other. The top 100 firms on the New Zealand Stock Exchange still had only $8.65 \%$ women directors in 2008 , up from $7.13 \%$ in 2006 and 5\% in 2003 (Human Rights Commission, 2008a). The Modern Apprenticeship scheme covering about 10,000 young people is mainly a male domain with the female proportion having increased only from $6.6 \%$ in 2003 through $8.5 \%$ in March 2006 to $9.3 \%$ in December 2007. Women were over one third of participants in tourism, public sector, retail, hospitality and seafood, but a miniscule proportion in the male traditional areas (15 out of 1536 in engineering and 5 out of 1618 in building and construction, the two largest groups overall). Clearly thirty years of work to encourage women into these trades has had little impact.

A piece of research undertaken by the New Zealand Council for Educational Research for the Ministry of Women's Affairs (MWA, 2008) investigated young people's career decisions with particular reference to gender segregation in the trades. It showed that Industry Training Authority courses, covering a much larger group of over 125,000 employees, show similar gender segregation. While $28 \%$ of trainees at September 2006 were women, only similar areas to the Modern Apprenticeship Scheme were gender balanced. In forestry, for example, only $9 \%$ of trainees were women, while hairdressing and community support services were female dominated. The aim of the study was to examine the interconnections between gender, gendered ideas, and career decision making on 'how and why' young people navigate to, or avoid trades-related pathways. It was commissioned as part of MWA's plan to improve the economic independence of New Zealand women and to decrease gender segregation in the workforce. The 
research included focus groups and interviews with young people ranging from junior secondary students to fully qualified employees, including 86 young women and men in trades-related pathways. It found that "gender stereotypes and dominant hetero-normative discourse continue to have a major influence on young people as they imagine and try out possible selves", even though "the narratives of some of the young tradeswomen interviewed disrupted - transcended even - gendernormative discourses to varying degrees" (Ministry of Women's Affairs, 2008, p v). Recommendations included initiatives involving many agencies on career decision making and extensions of the skill sets seen as needed in trade training to include financial information technology, customer service, people and relationship skills, as well as problem solving, innovation, creativity, design, complex project management, and the ability to adapt to change.

The fact that women in trades and factory jobs still often have to deal with discrimination is illustrated by one long running case. In June 2007, the High Court rejected Talley's appeal against the 2005 Human Rights Tribunal decision ruling that the company had discriminated against Nelson woman Caitlin Lewis. She had been a fish trimmer at Talley's Motueka fish processing plant from 1999 to 2001, and was prevented from being a filleter because she was a woman (for more detail on the earlier and recent material, see Hyman, 2007 and 2008). The Court ruled that this was a clear case of gender discrimination and awarded her compensation for lost earnings. The Human Rights Commission described the decision as a 'landmark' win against sex discrimination. The details of the judgement on the two jobs and practices at Talley's make fascinating reading. As in so many jobs, the realities of work go well beyond the job titles. The Court concluded that "the variations identified in the roles do not in our view alter the essential similarity" (High Court, 2007 [43]). The judgment noted that, though both jobs required superior knife skills, Talley's did not promote skilled trimmers, who were invariably women, to fill vacancies in the filleting line, preferring to employ totally untrained people and give them minimal instruction. "The reason she received less money was because she was made a trimmer, and the reason she was made a trimmer was because she was a woman - Talleys did not directly pay her less because she was a woman, but discrimination need not be deliberate" (ibid, [52]). It added that Talley's was entitled to pay one position more than the other, but could not prohibit people from moving between the jobs because of their sex.

NACEW's involvement in pay and employment equity includes a partnership with the Human Resources Institute of New Zealand to make available resources adapted from PEE tools for the private sector, "designed to assist employers to assess where they stand so they can be confident about their practices and address any inequities that become apparent." (HRINZ, 2008). It points out that: "men can also be adversely affected by unequal pay and employment. Although they are likely to earn more than women, the trade-off can be continuous, full-time, long-term involvement in employment even if they would like more choice around work and life options. New Zealand and international research shows that men, particularly young men, would like to be more involved with their children but lower women's pay is one reason why mothers continue to be the primary caregivers and fathers the primary breadwinners" (ibid). The rationale for ensuring pay and employment equity is covered, together with downloadable resources on the business case and how to do taster or full reviews.

Minimum code provisions, such as the minimum wage, sick leave, holiday provisions and parental leave, together with some government programmes, such as provision and subsidies for child care, and policies, for example on breastfeeding in the workplace, also have EEO impacts. Those which particularly affect parents with dependent children have substantial gender impacts in practice, since women continue to take the major role in family related responsibilities despite the point made above that many men would like to be more involved. The CTU estimates that of the 91,000 workers for whom the latest minimum wage boost (in April 2008 to $\$ 12$ per hour) directly led to a pay rise, 61,000 were women. Their submission in 2007 sought a minimum wage indexed to $66 \%$ of the average wage, which would raise it to $\$ 15$ per hour. They also sought an increase from $80 \%$ to $90 \%$ of the minimum wage for the trainee rate which recently replaced the youth rate. The Greens and Maori parties supported in 2008 election manifestos this immediate increase to $\$ 15$. Maori and Pacific workers, especially women, are even more concentrated than other women in low paid work.

Further improvements to parental leave eligibility, particularly for casual and seasonal workers, and to the length of leave and level of payment were foreshadowed in some Labour pre-election speeches but cut from early plans when the economic crisis hit and are highly unlikely to be taken up by a National led government. Creating family friendly workplaces and assisting individuals to secure a satisfactory work life balance is now a common mantra. The Flexible Employment Arrangements Act, 2007 guarantees a right to request flexible working hours by parents with young or disabled children. While requests rather than major obligations are imposed by this approach, it could change the climate as has occurred with similar legislation in the U.K. However, there was clear evidence in the PEE reviews of part time work and requests for flexibility being seen as a lack of commitment to the job and holding back career options, especially for women. An area where some progress for women is being made is that of protection for breastfeeding in the workplace. In addition to legislating for minimum meal and rest break requirements, amendments to the Employment Relations Act in 2008 require employers to provide, where reasonable and practicable, facilities and breaks for breastfeeding. The qualification may limit real impacts, but at least a code of employment practice and guidelines is supplied. However, some employers still flout anti discrimination law with respect to parenting. A waitress and a bar manager have recently been awarded compensation by the Employment Relations Authority for wrongful dismissal following each informing their employers of their pregnancy. 
Clearly issues of how to ensure that employees can combine paid and caring work are receiving ever more attention, although as already indicated, there is a great deal of ambivalence in dealing with them, The EEO Trust, the Families Commission and the Department of Labour are among the organisations advocating for family friendly cultures and policies, while a good edited collection explores the complexities and nuances for both women and men, including unpaid caregivers, Maori and Pacific women, and older women parenting for the second time (Waring and Fouche, 2007). The Families Commission researched perceptions and experiences of flexible work using focus groups, case studies and a survey of 1,000 people. The benefits for families were clear in terms of reduced stress levels and improved quality of time with families. However, substantial numbers reported that they did not have the flexibility they wanted while others experienced a trade off of flexibility for lower pay and status. The culture of a workplace played a big part in whether or not staff felt able to seek flexible work arrangements, with negative attitudes of managers and colleagues the main barrier, even when there were, theoretically, supportive policies in place (Families Commission, 2008a). Investigating how parents working non-standard hours organised care for their preschool children, the Commission found that while a few had ideal childcare arrangements, others were not adequately supported or had to make complex arrangements (Families Commission, 2008b). An EEO Trust pilot research project covering employees from 15 workplaces explored the relationships between work-life balance, employee engagement, discretionary effort and productivity. The relationships which emerge are complex, but confirm previous literature including that of the Families Commission which indicates that just having work-life initiatives is not enough to achieve increased performance and productivity - there needs also to be a supportive workplace culture. Senior managers, who are a crucial factor in the implementation of work-life strategies, tended to rate their workplace's work-life culture higher than their lower level staff (EEO Trust, 2007).

Caveats about the reality of family friendly (or work life balance or flexibility in workplaces) rhetoric and policies have already been raised. Some commentators go further in their sceptical analyses, for example arguing that social and economic goals in this area are not mutually compatible. One thesis on the politics of work life balance find that work life balance has "negative implications for fairness and equality, amongst New Zealand workers and between men and women. However, the gender-neutral and individualised language of work life balance masks its discriminatory systemic effects" (Domett, 2006, p 1). Tania Domett conducted two organisational case studies as well as interviewing key stakeholders She found, perhaps inevitably, that work life balance is primarily sold to business for its efficiency gains - or "its capacity to reinforce and support rather than cushion market forces" (ibid, p 58). This tends to lead to a two tier approach where valued white-collar professional workers, mainly women, have easier access to its provisions, but nevertheless often lose out on career progress, as suggested earlier from PEE work.
Meanwhile, men tend to be constrained from attempting to use such policies because of the persistence of the woman as caregiver, men as breadwinner model and the threats to their pay and careers. "In this way, both men and women are captive to historically embedded gender roles, structures, and norms" (ibid). And lower level workers have less bargaining power and their insecure patterns of perilous work may be misrepresented as allowing work life balance.

A related challenge to the whole basis of the approach of EEO implementation in practice includes a detailed case study of an unsuccessful application for some special conditions (Simon-Kumar, 2008). This concerned a full time woman employee in the public service who, as a sole parent with child care issues, sought to work additional hours at one period (when her child was overseas with the father) to accumulate some time off in lieu for a period when she would have sole custody. Such time in lieu was not within current policy in the employee's position but was viewed by the applicant as reasonable in her circumstances, and given the policies, guidelines, and strategies of her organisation, which is also covered by the State Sector Act EEO provisions mentioned earlier. It was declined on the basis that work life balance initiatives "need to be balanced with fair and equitable treatment of all staff, meeting business requirements, and being consistent with other HR policies" (ibid, p 28), with the particular area of work seen as not suitable for time banking and the lack of normal time in lieu provisions in her position. Simon-Kumar uses discourse analysis to discuss the different interpretations of fairness, equity, and discrimination adopted by the applicant and the employers. For the claimant, fairness should recognise difference and social disadvantage, while for the employer it was interpreted in terms of equal and the same treatment for all. The employer's understanding of EEO is largely framed by a liberal managerial discourse, rather than the more radical model which underlies the social justice EEO and collectivist claims for disadvantaged groups

\section{Gender issues - are women still disadvantaged in the labour market?}

Earlier sections of this paper have pointed to areas where women remain disadvantaged in the labour market, including their predominance in low paid work. In addition, there is only very slow progress on closing the overall gender earnings gap - the female male earnings ratio in the June 2008 Quarterly Employment Survey is $87.4 \%$ for average hourly earnings and $79.6 \%$ for average weekly earnings. In addition, public sector and recent graduates starting salaries data, from NZVCC surveys, appear to indicate an ongoing problem. However, with New Zealand women's educational achievements having caught up to or surpassed those of men's in many respects, some commentators argue that equality has been achieved or exceeded and male disadvantage needs addressing, at least in the education system. Women now constitute over half of new graduates, in $200663 \%$ of Bachelor degree completions, $58 \%$ of Masters and $51 \%$ of Doctorates. But achievements by women are at times 
portrayed as being at the expense of men and any special provisions to lift the position of Maori and other ethnic groups or women regarded with suspicion, whether in the educational system or in employment. This seems unfortunate when in fact the educational outcomes for both genders is improving while disadvantages in the labour market continue for women. Alarm about the female majority of students may be excessive when the number of tertiary students is still growing fairly rapidly and with it the number of male students - the number of females is simply increasing faster. More sophisticated analyses of gender and ethnic gaps, including the heterogeneity of choices and outcomes for both women and men and the role of choice are called for in a paper discussing the issues in detail - when does a minor difference become a worrying disparity? (Callister et al, 2008).

One aspect of these debates is whether there is an ongoing justification for women-only scholarships. This has been queried by Paul Callister, lead author of the paper cited above, who has asked the Human Rights Commission to consider the question. The legal justification for exemption of women only scholarships from the gender discrimination provisions of New Zealand human rights legislation rests on redressing past discrimination. Callister believes that women-only scholarships should now be made gender-neutral so anyone in need could apply. $\mathrm{He}$ also asked the Commission to rule on the legality of men-only scholarships - in fields such as early-childhood-teacher training and nursing where men have long been underrepresented. As this is analogous to the case for women only scholarships, the case is strong. The HRC is working on the broader issue, but has pointed out that where scholarships for women, men or any other specified group are offered by charitable trusts, they are exempt from the provisions of the Human Rights Act 1993. However, the social case needs examination - and there are indeed more scholarships for women only than for men only. Many of these are aimed at helping women into areas where they are still underrepresented engineering, physical sciences, computing. A case can still be made for these and for second chance scholarships for older women returning to education, given that societal and family expectations meant that women were less likely to get a first chance when they were young.

Some raising similar issues have done so in a less reasoned manner. For example, Massey Pro Vice Chancellor James Chapman, at a School of Education graduation in which only 15 of 158 graduates were women, referred to the significant decline in interest of males in primary school teaching, He speculated that one of the main factors was 'the gradual feminisation of education in New Zealand, in terms of policies as well as teacher gender'. Whether it is desirable to attract more men to teaching, and if so how, is worth debating. One way might be to pay teachers more, both male and female, particularly in technology and mathematics, the chief areas of shortage. But Chapman went further, according to the Manawatu Standard, 22 May, 2007, saying "New Zealand now has one of the largest gaps in the world between male and female achievers, with men coming out the losers." Given the labour market gender differences outlined above, this cannot be substantiated.

\section{Equal employment opportunity - age, disability and ethnicity}

With the only legislative underpinnings for EEO in the private sector being the anti discrimination provisions of industrial relations and human rights law, the main developments have been in education and provision of resources to encourage employers to make the best use of all groups of employees - together with a diverse workforce and the workplace flexibility discussed earlier. For example, the EEO Trust's Work \& Life Awards give publicity to firms making effective efforts with respect to such flexibility and hopefully inspire others as well as suggesting specific approaches. The Trust also alternates annually a Diversity Survey and a Work-Life Survey. The Diversity Survey measures how well New Zealand workplaces access and value the talents of a diverse population and tap into their creativity, initiative, intelligence and skills. The 2007 Survey was completed by 364 organisations which employed 242,813 people. It found that best practice organisations had lower staff turnover than others.

A combination of the ageing of the population and skill shortages that have led to seeking employees overseas, have created a particular focus on older workers and migrants. The Equal Employment Opportunities Trust (http://www.eeotrust.org.nz/) publishes research, makes good practice awards and assists employers with EEO resources. Benefits to firms adopting such policies are emphasized in terms of a satisfied workforce and productivity enhancement. It should be noted that the research discussed throughout this section, particularly when individual views of employers and employees are reported, is subject to a number of provisos. Contributing to most of these surveys is entirely voluntary, so that those most interested and favourable to the perspectives of valuing diversity are likely to take part. Employers and managers may also, inevitably, illuminate their organisations in the best possible light. Many of the publications give a 'half full, half empty' evaluation of the situation, which probably reflects realities, but there is little objective evidence to evaluate how effective the resources are, what proportion of employers are convinced and behave accordingly, and what proportion of disadvantaged groups are still subject to discrimination.

With respect to older workers, these guides to employers include Valuing Experience (Human Rights Commission et al, 2008). It is based on the perspective that smart organisations are redesigning work to retain older workers, as they need to do with the ageing of the New Zealand workforce. Almost a quarter of New Zealand's workforce is aged between 50 and 64 and the proportion will increase, together with those over 65 . The guide provides information on older workers' rights and responsibilities together with tips for employers. It includes information on recruiting and retaining older workers, work design, job structure, effective supervision, 
managing performance, training and development, and motivation and rewards. Recognising that older workers are a valuable resource for employers at a time of demographic change, skill shortages, changing markets, and the need for increased productivity, the report emphasises the importance of retaining the skills, knowledge and experience of older employees and of not overlooking their potential when recruiting. It includes 12 tips for employing older workers and other downloadable checklists. Employers are enjoined that they will need to pay attention to the needs, aspirations and expectations of older workers, involving a willingness to do the following (extract only):

"Treat people as individuals - one size rarely fits all

Deliberately consider the needs of older employees and make sure that policies and practices work as well for them as for younger employees

Involve older workers in decisions that will impact on them

Develop a culture that values age and experience"

The EEO Trust is giving similar messages, with reports based on employers' and recruitment agencies' experience. Research with EEO Employers Group members showed that many place a high value on older workers, appreciating their reliability, experience, stability and loyalty (EEO Trust, 2008a), Recruiters reported more mixed experience of appreciation and resistance, the latter largely related to perceptions concerning energy levels, flexibility, and ambition. They stressed the importance of a skills-based focus during the recruitment process to ensure that the best person was hired, regardless of age. Some recruitment consultants still heard of people in their 50s having difficulty obtaining an interview, let alone a job, but most believed that employers' attitudes to older workers were becoming increasingly positive (EEO Trust 2008b).

The New Zealand Disability Strategy is a tool to improve the lives of people with disabilities, including their position in the labour force. Its Implementation Review reported on the progress made by central government agencies implementing the strategy between 2001 and 2007. It involved wide consultation with disabled people's organisations and support providers as well as government agencies. One aspect of the strategy relates to meaningful employment and adequate income - objective 4 requires the provision of opportunities in employment and economic development. In 2001, an estimated $44 \%$ of disabled adults were in the workforce as against $74 \%$ of non-disabled adults, with a consequent large income gap. While there has been considerable improvement in provision of employment opportunities and removal of barriers, there is a perception of a main centre-rural gap and less opportunity for those with more complex needs or intellectual disabilities. The report states that throughout the interviews it was clear that many disabled people continue to feel a sense of frustration and disappointment at the slow pace of change (Office for Disability Issues, 2007). Adoption of the Convention on the Rights of Persons with Disabilities by the United Nations on 13 December, 2006, with New Zealand signing in 2007, was followed by the passage of necessary changes in legislation for compliance prior to ratification. Giving voice, visibility and legitimacy to disabled people and their issues, it should provide a further tool for reducing discrimination and increasing opportunity, but clearly there is a long way to go.

Immigrants, especially those with high skills which they often struggle to get fully recognised in New Zealand, are another group rightly targetted under the diversity umbrella. Some industries such as dairying are increasingly reliant on migrant workers while others with labour and skills shortages could benefit from actively recruiting among these groups. Again checklists have been developed for employers to demonstrate good practice, together with examples (Human Rights Commission, 2008b). Necessary conditions include zero tolerance of racial discrimination in workplaces, accommodating religious diversity at work, good training and induction systems, and assistance with improving English language competencies. The HRC publication also encompasses both accounts of the barriers and discrimination that migrant workers face and success stories that profile businesses where migrant employees are valued and crucial to productivity.

Outcomes for Maori and Pacific employees are gradually improving, in terms of employment growth, reduced unemployment, wages and self employment rates, but average levels on all indicators remain well below those of the overall population, and not all are narrowing. For example, Maori average hourly earnings rose by an average of $4.2 \%$ per annum between June 2002 and June 2007 , from $\$ 14.33$ to $\$ 17.58$, while the economy-wide rate grew by $5.1 \%$ on average from $\$ 16.71$ to $\$ 21.41$, so that the ratio actually fell from $85.8 \%$ to $82.1 \%$. On the other hand, the number of Maori employed grew by $8.7 \%$ in the year to June 2007, as against an employment growth of only $0.8 \%$ among non-Maori, while Maori unemployment fell to $7.6 \%$ for the year to June 2007 , the lowest rate ever recorded. However, this remains well above the $3.7 \%$ overall rate (Department of Labour, 2007a) For Pacific peoples, too, the picture is mixed, with above average employment and wage growth in the same five years, reductions in unemployment rates and in the amount by which they exceed the general rate. However. Pacific people are less than $1 \%$ of CEOs/company directors, are only $2.1 \%$ of production managers in manufacturing where they are $7.9 \%$ of all employees, and only $2 \%$ of senior management in the public service, where they are $7 \%$ of employees (Department of Labour, $2007 b)$. There is a long way to go with respect to EEO for these groups as employees, while the improvements are largely a matter of favourable economic conditions and improved educational outcomes rather than specific policies.

Generally, any such ethnicity based special policies, whether in employment, social welfare, health or elsewhere, have been politically challenged in recent years, resulting in a retreat from them by the previous Labour government, under the mantra needs-based rather than race-based measures to mitigate disadvantage. Paul Callister (2007) has examined the nature and history of special measures in New Zealand, and their strengths and weaknesses, reflecting on the circumstances which may 
make such measures effective, as well as politically acceptable. The Human Rights Commission supported the research and have issued guidelines for organisations on measures to ensure equality and reduce ethnic disadvantage, pointing out that human rights legislation specifically upholds special measures in particular circumstances. As with gender, discussed above, such special measures directed to a particular ethnic group are not discriminatory when applied to 'those persons or groups that need or may reasonably be supposed to need assistance or advancement in order to achieve an equal place with other members of the community'. The Commission consider that such special measures remain an important policy tool and that properly used, they can make a major contribution to reducing the effects of discrimination.

Both Maori and Pacific communities, together with the relevant government agencies, place major emphasis on the realisation of the full potential of their peoples, based on autonomy, entrepreneurship, self-direction, innovation, and internal leadership. Such a direction would also make these populations less dependent on the behaviour of employers and managers from outside their groups. "The success of future economic development will be based on Maori having the capacity to lead, influence and make positive decisions for themselves to ensure economic growth". (Te Puni Kokiri, 2007, p 40). On similar lines, the three key outcomes emphasised by the Ministry of Pacific Island Affairs Statement of Intent 2008 - 2011 (2008), accompanied by a 2007 Pacific Economic Action Plan and a Pacific Women's Economic Development Plan, are for Pacific peoples to participate fully in New Zealand's economy, for the social wellbeing of Pacific peoples to be enhanced, and for Pacific peoples' cultures and heritage to be supported, developed, and valued. Business development, growth industries and entrepreneurial culture and leadership are again stressed in these plans.

\section{Conclusion and future prospects}

The picture outlined above of the last two years shows many reports and some progress, albeit slow, in a number of areas. The prospects for the future are of concern at a time of world economic uncertainty and likely increases in unemployment - where low paid and EEO groups are often the first to suffer. The election policies of the parties indicated that those elected to government are largely committed to market solutions, educational progress for all, and enhanced growth to improve the position of these groups rather than more specific policies which Labour led governments delivered, albeit to an increasingly limited extent. Voluntary codes and educational resources are likely to continue to be promoted.

Most of the institutions discussed above are also likely to survive. The EEO Trust was instituted by the 1990 National Government after it repealed Labour's more interventionist Employment Equity Act. NACEW has survived many National governments, while the PEE Unit is supported by its department and has an assistance rather than interventionist role. The Ministry of Women's
Affairs' existence is safe for now. Don Brash when leader of National had threatened to abolish it, but John Key, perhaps through concern for the gender gap in women's votes between Labour and National, made Jackie Blue spokesperson when elected leader. He has now appointed Pansy Wong as Minister of Women's Affairs, although coverage of this appointment was miniscule - and the budget may well be cut. However, the prospects for real outcomes from the work of the PEE Unit, NACEW, and the Ministry of Women's Affairs are even less rosy with respect to pay equity and dollars for pay increases in caring work under the new National led government than they would have been under a Labour led one. Regular speeches about the excessive size and cost of the public service and further freeing up of the labour market are far from reassuring. The National party in opposition sponsored the Employment Relations (Probationary Employment) Amendment Bill, which would have introduced a 90-day probation period for new employees. Its purpose was stated to be to enable employers to take a chance with new employees, without facing the risk of expensive and protracted personal grievance procedures. Proponents argued that it would enable people who have not had previous work experience to find their first job and make it easier for people re-entering the workforce. It would have meant no right of appeal against unfair dismissal in the first 90 days. Union critics argue that it would create a category of 'disposable worker'. It was defeated, but a somewhat less sweeping version (businesses with under 20 employees) is being debated under urgency during December 2008 - whether an even stronger version will be introduced in 2009 is yet to be seen. Either way, reductions in labour market protections are involved, with the lower paid most affected.

\section{Future research}

Given the prospects outlined above, monitoring of EEO provisions and outcomes remains essential However, exortation and monitoring needs to be accompanied by more in depth evaluation and research on what works in this difficult area. Statistical analyses of labour market outcomes and change at a broad level are not enough in themselves. In depth qualitative and quantitative research that attempts to disentangle the factors involved is still rare and to be encouraged.

\section{References}

Burns, J. (2007). Who Cares? Women in the Homecare Industry

http://www.neon.org.nz/newsarchive/jb/

Callister, P. (2007). Special measures to reduce ethnic disadvantage in New Zealand: an examination of their role Victoria University of Wellington Institute of Policy Studies.

Callister, P., Leather, F. and Holt, J. (2008). Gender and tertiary education: Is it useful to talk about male disadvantage? Victoria University of Wellington Institute of Policy Studies, Working Paper 08/10. 
Department of Labour (2007a). Maori labour market outcomes

http://www.dol.govt.nz/publications/lmr/lmrmaori-outcomes.asp

Department of Labour (2007b). Pacific peoples labour market outcomes at a glance .http://www.dol.govt.nz/publications/lmr/l mr-pacific-outcomes-summary.asp

Department of Labour Pay and Employment Equity Steering Group. (2008). October 2008 Newsletter http://www.dol.govt.nz/services/PayAndEmploym entEquity/news/newsletters/oct08.asp

Domett, T. (2006). The politics of work life balance: the New Zealand case MA thesis, University of Auckland.

EEO Trust. (2007). Work-life balance, employee engagement and discretionary effort pilot research downloadable

http://www.eeotrust.org.nz/research/index.cfm?cac he $=120912$

EEO Trust. (2008a). Older workers: employers speak out downloadable at http://www.eeotrust.org.nz/research/index.cfm?cac he $=120912$

EEO Trust. (2008b). Boomers and beyond: recruiters tell their stories downloadable at http://www.eeotrust.org.nz/research/index.cfm?cac he $=120912$

Families Commission (2008a). Give and take - families' perceptions and experiences of flexible work in New Zealand downloadable at http://www.nzfamilies.org.nz

Families Commission (2008b). Juggling Acts - How parents working non-standard hours arrange care for their preschool children downloadable at http://www.nzfamilies.org.nz

High Court. (2007). Unreported, High Court Wellington, CIV 2005-485-1750 (14 June 2007) Simon France $\mathrm{J}$, Ms S Inceson \& Dr A Trlin. http://www.hrc.co.nz/hrc_new/hrc/cms/files/docu ments/15-Jun-2007 13-26-

56_Talleys_June_07.pdf

Human Rights Commission (2008a). New Zealand Census of Women's Participation downloadable at http://www.hrc.co.nz/home/hrc/newsandissues/eeo commissionerwomenlockedoutofboardroom.php

Human Rights Commission (2008b). From brain drain to brain gain: migrant workers in New Zealand http://www.neon.org.nz/documents/Brain\%20Gain $\% 20-\% 20$ Migrant $\% 20$ workers $\% 20$ in $\% 20$ NZ.pdf

Human Rights Commission, Retirement Commission, EEO Trust, Business New Zealand, CTU and
Canterbury Employers' Chamber of Commerce (2008). Valuing Experience: a practical guide to recruiting and retaining older workers Report from Top Drawer Consultants, http://www.neon.org.nz

Human Resources Institute of New Zealand. (2008). Play Fair - Pay and Employment Equity http://www.hrinz.org.nz/Site/HR_Info/Pay_and_E mployment_Equity/default.aspx

Hyman, P. (2007). Talley's lose fish filleting pay case How big a victory for employment equity? Women's Studies Association Newsletter 28(1), p 9-10.

Hyman, P. (2008). 'Pay Equity and Equal Employment Opportunity - Developments 2004/2006 and Evaluation' in Proceedings of Twelfth Conference On Labour, Employment And Work (eds S.B. Blumenfeld and G. Lafferty) Wellington: Victoria University of Wellington, pp ??

Ministry of Pacific Island Affairs. (2008). Statement of Intent $\quad 2008 \quad$ - 2011 http://www.mpia.govt.nz/resources/pdfs/SOI\%202 008.pdf

Ministry of Women's Affairs (2008). Trading choices young people's career decisions and gender segregation in the trades, Report prepared for MWA by NZCER http://www.mwa.govt.nz/newsand-pubs/publications/trading-choices-youngpeoples-decisions-and-gender-segregation-in-thetrades

National Advisory Council on the Employment of Women (2007). Forty years of work 1967-2007 http://www.nacew.govt.nz/about/history/40/40year s/40page01.html

National Advisory Council on the Employment of Women (2008). Critical issues for New Zealand women's employment, now and in the future http://www.nacew.govt.nz/publications/general/cri tical-issues/critical-issues_02.html

Office for Disability Issues. (2007). New Zealand Disability Strategy Implementation Review 20012007. http://www.odi.govt.nz/nzds/progressreview/index.html

Simon-Kumar, R. (2008). 'Approve to Decline': A feminist critique of 'Fairness' and 'Discrimination' in a case study of EEO in the New Zealand Public Sector, Women's Studies Journal, 22/1, p.20-36.

Te Puni Kokiri. (2007). For Maori Future Makers http://www.tpk.govt.nz/en/in-print/our-

publications/publications/for-maori-future-makers/ 
Waring, M. and Fouche. C. (eds) (2007). Managing mayhem: work-life balance in New Zealand, Wellington: Dunmore Publishing Ltd.

\section{Author}

Prue Hyman

Senior Lecturer/Supervisor

Gender and Women's Studies

Victoria University of Wellington

P.O. Box 600

Wellington 6140

Prue.Hyman@vuw.ac.nz 